\title{
Thermal and Anti-Corrosive Properties of Titanium Dioxide/Epoxy Resin Composite Coating for Steel Preservation in a Marine-Environment
}

\author{
O. Dagdagi,2, A. El Harfi ${ }^{2}$, A. El Bachiri ${ }^{3}$, S. Jodeh ${ }^{2,4, *}$ \\ ${ }^{1}$ Laboratory of Industrial Technologies and Services (LITS), Department of Process Engineering, \\ Height School of Technology, Sidi Mohammed Ben Abdallah University, \\ P.O. Box 2427, 30000, Fes, Morocco. \\ ${ }^{2}$ Laboratory of Organic Chemistry, Catalysis and Environment, Department of Chemistry, \\ Faculty of Science, Ibn Tofail University, BP 133, 14000 Kenitra, Morocco. \\ ${ }^{3}$ University Department, Royal Naval School, Sour Jdid Boulevard, Casablanca, Morocco. \\ ${ }^{4}$ Department of Chemistry, An-Najah National University, P. O. Box 7, Nablus, Palestine. \\ *Corresponding author: sjodeh@hotmail.com
}

Received 26/11/2017; accepted 20/10/2020

https://doi.org/10.4152/pea.2021390303

\begin{abstract}
This study reports the evaluation of the anticorrosive performance of polymer epoxy resin, namely, Diglycidyl ether 4, 4'-dihydroxydiphenylsulfone (DGEDDS) and its polymer composite reinforced with Titanium Dioxide $\left(\mathrm{TiO}_{2}\right)$, for carbon steel (CS) corrosion, in 3\% wt. $\mathrm{NaCl}$, using experimental analyses. Thermal, electrochemical and morphological techniques were used to demonstrate the anticorrosive effectiveness of the standard epoxy resin (MP1) and its $\mathrm{TiO}_{2}$ composite (MP2). The effect of UV irradiation (for $2000 \mathrm{~h}$ ), on the effectiveness of MP1 and its $\mathrm{TiO} 2$ composite (MP2), showed that $\mathrm{TiO}_{2}$ presence appreciably enhanced the protection efficiency effect of MP1.
\end{abstract}

Keywords: Polymer composite, Titanium Dioxide, carbon steel, UV exposure and 3 wt. $\% \mathrm{NaCl}$.

\section{Introduction}

Organic coatings form a class of high-performance material, chemically resistant, used in protective applications coatings, as one of the ways to combat corrosion [1, 2]. Generally, epoxy based coatings are amongst the most common industrial polymers which have been applied to protect various metals from corrosion in aggressive environments [3]. Epoxy coatings have been used as a structural or engineering adhesive for the construction of aircrafts, automobiles, etc. The excellent chemical resistance, good adhesion to the underlying metal surfaces, outstanding thermal stability, good mechanical properties, and electrical insulating 
properties, make epoxy resins an ideal coating material for various applications $[4,5]$.

For this purpose, epoxy coatings reduce metals corrosion rate by acting as an effective physical barrier between metals and corrosive environment. However, owing to wear and abrasion, epoxy based coatings also fail to offer long-term corrosion protection. During the curing process of epoxy coatings, the shrinkage of epoxy resin takes place and absorbs water, air from the environment, and this, in turn, makes microspores in the epoxy coatings. The pores in the coating facilitate to some extent the diffusion of corrosive species such as oxygen, water and ions at the metal/epoxy interface, and initiate the corrosion process, depleting the coating [6-8].

However, in practice, all organic coatings are permeable to corrosive species, such as oxygen, water and ions, to some extent $[9,10]$. In the last few years, the study of the performance of nanocomposite coatings has been in the center of attention of organic coating scientists, due to their beneficial properties [11, 12]. Various nanoparticles, such as $\mathrm{ZnO}$ [13], $\mathrm{ZrO}_{2}$ [14], $\mathrm{CeO}_{2}$ [15], $\mathrm{CaCO}_{3}$ [16], $\mathrm{Fe}_{2} \mathrm{O}_{3}$ [17], $\mathrm{SiO}_{2}$ [18] and $\mathrm{TiO}_{2}$, have, therefore, been employed as reinforcements, in order to improve coatings performance in the corrosive environments [19]. They have been introduced into coatings, to investigate their effects on protective properties. Titanium dioxide $\left(\mathrm{TiO}_{2}\right)$ is a multi-purpose nanoparticle, utilized to produce multifunctional nanocomposite coatings, because of its high refractive index, its strong UV light absorbing capabilities and its resistance to ultraviolet light [20].

Furthermore, $\mathrm{TiO}_{2}$ is an inorganic UV-absorber, exhibiting more stability than the usual organic UV absorbers or light stabilizers. Additionally, $\mathrm{TiO}_{2}$ nanoparticles do not cause/accelerate polymer degradation, compared to UV-absorbent $\mathrm{TiO}_{2}$ nanoparticles [20].

The objective of this research is to determine the effect of $\mathrm{TiO}_{2}$ nanoparticles addition to standard epoxy coatings on their UV stabilizing and anticorrosive protective properties, by Electrochemical Impedance Spectroscopy (EIS). EIS has been used to measure the performances and to monitor the degradation of the coatings protective properties during UV exposure. Equivalent circuit model was proposed to interpret the electrochemical impedance data for the herein studied coated systems.Therefore, the results evidenced excellent UV stabilization, corrosion resistance and application of the new composite coating.

\section{Experimental section \\ Materials}

Diglycidyl ether 4, 4'-dihydroxydiphenylsulfone (DGEDDS) epoxy resin was synthesized in our laboratory (Fig. 1), and the 4, 4'-Methylene dianiline (MDA) curing agent was supplied by Sigma-Aldrich. Corrosion experiments were performed using carbon steel panels with the following chemical composition: Fe 98.70\%, C 0.11\%, Si 0.24\%, Mn 0.47\%, Cr 0.12\%, Mo 0.02\%, Ni 0.1\%, Al $0.03 \%, \mathrm{Cu} 0.14 \%, \mathrm{Co}<0.0012 \%, \mathrm{~V}<0.003 \%$ and $\mathrm{W} 0.06 \%$ ) [21]. 


\section{Synthesis of diglycidyl ether 4, 4'-dihydroxydiphenylsulfone}

Diglycidyl ether 4, 4'-dihydroxydiphenylsulfone (DGEDDS), shown in Fig. 1, was obtained by condensation of epichlorohydrin and 4, 4'-dihydroxydiphenylsulfone. The yield of the DGEDDS was of about $89 \%$.
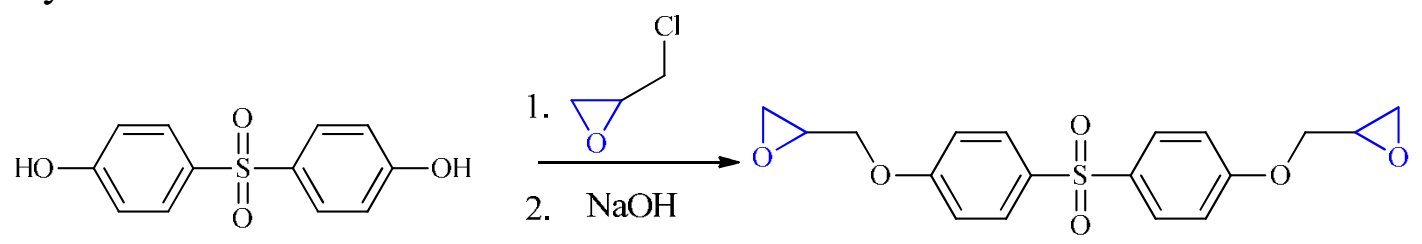

Figure 1. Synthesis route of DGEDDS.

\section{Curing process of Diglycidyl ether 4, 4'-dihydroxydiphenylsulfone}

Epoxy resins can be processed into thermally cured polymers, through many chemical compounds acting as bridging agent or hardeners, during the implementation [22]. Curing agents can be divided into amine-type curing agents, alkali curing agents, anhydrides, and catalytic curing agents, according to their chemical compositions. We limited ourselves to one hardener class: primary diamine aromatic. According to their chemical structure, the aromatic compounds provide very good thermal stability and mechanical properties to the resin. Therefore, they are often used for high-tech applications.

Our curing agent was performed by an aromatic primary diamine. The chemical structure is as follow (Fig. 2) [23]:<smiles>Nc1ccc(Cc2ccc(N)cc2)cc1</smiles>

Figure 2. Chemical structure of 4, 4'-Methylene Dianiline (MDA) used as curing epoxy resins.

The reaction between epoxide and diamine is a bi-molecular reaction of the addition of the primary amine functions on the epoxide cycles, by the opening of oxirane cycles (Fig. 3).

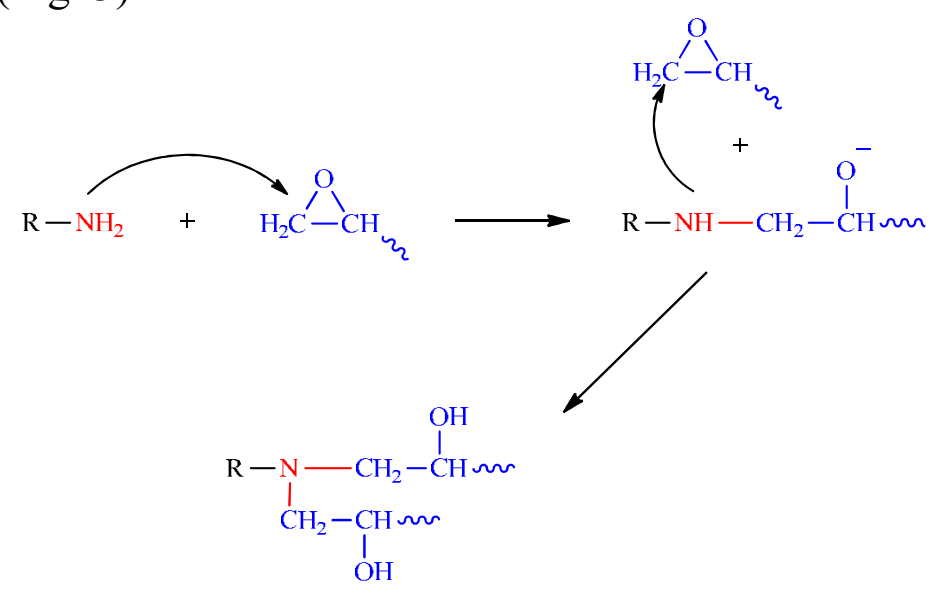

Figure 3. Proposed mechanism for the reaction of an epoxy resin and a primary diamine as a hardener. 
Polymer networks are formed from functional precursors, by reactions between their functional groups, resulting in a bond formation. The crosslinked branched structures are generally formed by this method. The system consisting of a tetra functional epoxy and a bi-functional diamine remains a typical example. Primary amine sites, in this system, act as chain extenders, while secondary amines produce branches (Fig. 4).

The action of 4, 4'-ethylene dianiline on the epoxide is described by the following reaction [24]:

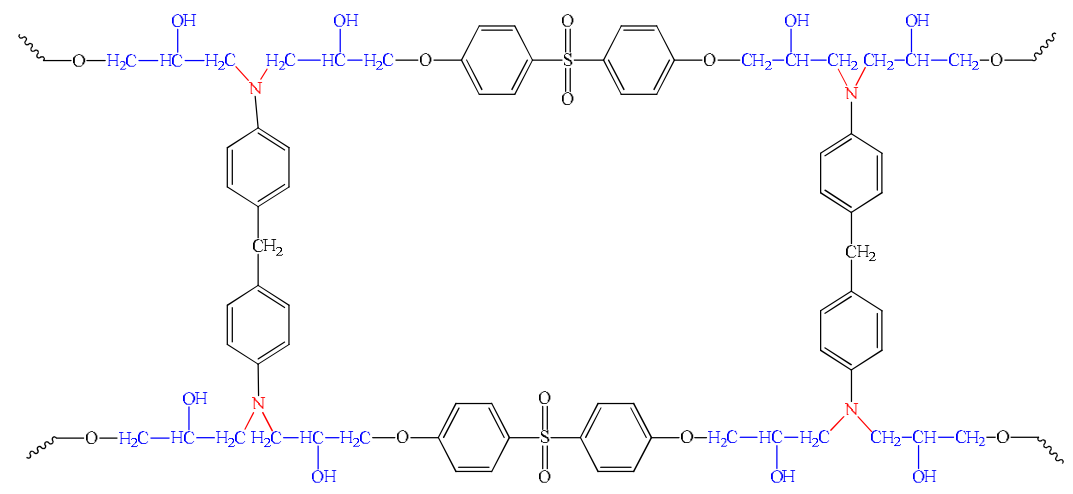

Figure 4. Structure of idealized epoxy resins and primary diamines as a hardener.

Mixing the epoxy resin with the hardener, prior to crosslinking, is performed differently, depending on the used hardening agent. In the protocol that is adopted by Levan [25], methylene dianiline, crystallized at room temperature, is placed in an oven at $120{ }^{\circ} \mathrm{C}$ (a temperature above its melting point), while the resin is carried out at $60{ }^{\circ} \mathrm{C}$. Once melted, the curing agent (MDA) is mixed with the epoxy resin, to provide a single fluid phase, being then at $70^{\circ} \mathrm{C}$.

\section{Ratio Calculation}

Calculation of stoichiometric coefficients

In order to get the maximal crosslinking density properties when we harden a difunctional epoxy resin with a hardener (especially amines), we used the given data (EEW and AHEW) from the technical sheet of the different reactants.

The Epoxy Equivalent Weight (EEW) of the DGEDDS epoxy resin is calculated as below (Equation 1):

$$
\mathrm{EEW}=\mathrm{M}(\text { Epoxy }) / f=\mathrm{M}(\mathrm{DGEDDS}) / 2=362 / 2=181 \mathrm{~g} / \mathrm{eq}
$$

where $\mathrm{M}$ is the Molar mass of the resin $(\mathrm{M}=362 \mathrm{~g} / \mathrm{mol})$, and $\mathrm{F}$ is the Functionality of the resin $(\mathrm{f}=2)$.

Calculating the equivalent amine (Amine Hydrogen Equivalent Weight: AHEW) is determined as below (Equation 2):

$$
\mathrm{AHEW}=\mathrm{M} \text { (curing agent) } / f=\mathrm{M}(\mathrm{MDA}) / 4=49,56 \mathrm{~g} / \mathrm{eq}
$$


where $\mathrm{M}$ is the molar mass of the used hardener and $\mathrm{f}$ is the functionality of the hardener.

Calculation of the weight ratio

The calculation of the weight ratio is determined as below (Equation 3):

Mix ratio by weight $=($ AHEW $/ \mathrm{EEW}) \cdot 100=(49,56 / 181) \cdot 100=27,43 \mathrm{~g} / \mathrm{eq}$

The resin (DGEDDS), with an equivalent weight of $181 \mathrm{~g} / \mathrm{eq}$ of epoxy, is being mixed with an amine hardener (MDA), with an equivalent weight of 49, $56 \mathrm{~g} / \mathrm{eq}$ of amine.

For a complete reaction, with no unreacted components left over, one equivalent of epoxy must react with one equivalent of $\mathrm{N}-\mathrm{H}$ amine.

One equivalent epoxy weighs $181 \mathrm{~g}$. One equivalent amine weighs 49, $56 \mathrm{~g}$. The mix ratio by weight is $181 \mathrm{~g}$ epoxy per $49,56 \mathrm{~g}$ of amine.

The amount of the required MDA for the hardening of $100 \mathrm{~g}$ of DGEDDS is $27,43 \mathrm{~g}$.

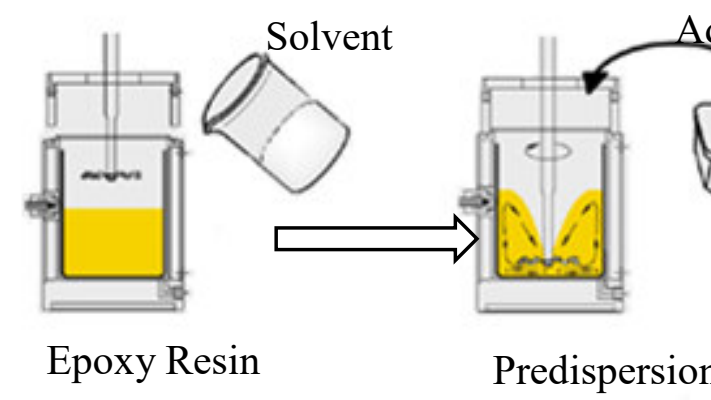

Epoxy composite coatings Carbon steel
Additive

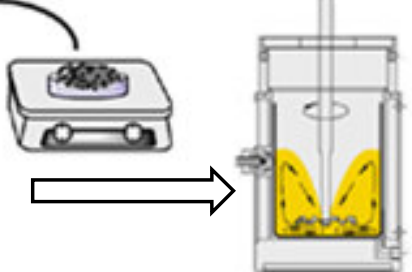

Dispersion

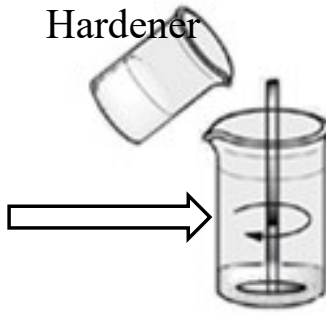

Formulations
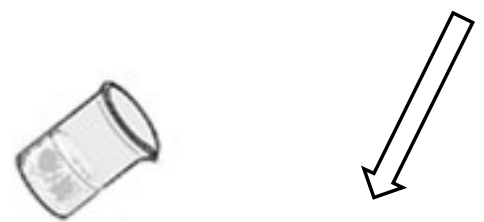

Carbon steel

Figure 5. Schematic of epoxy composite coatings preparation method.

\section{Formulation composition and steel coating}

Two epoxy formulations, which differ in the UV stabilizer and anticorrosive additive, were prepared. More specifically, these two formulations contained DGEDDS and MDA hardener in stoichiometric amounts, $\mathrm{MP}_{1}$, and 5 wt. $\% \mathrm{TiO}_{2}$ $\mathrm{MP}_{2}$, as UV stabilizer and anticorrosive additive. Fig. 5 shows the schematic of epoxy coatings preparation.

The prepared coatings were applied on the steel sheets by mechanical agitation, for about $10 \mathrm{~min}$, at room temperature. The coated substrates were cured at $70{ }^{\circ} \mathrm{C}$ for $24 \mathrm{~h}$. The coatings thickness was in the range of $170 \pm 10 \mu \mathrm{m}$. 


\section{Characterization methods}

\section{Coating evaluation under accelerated conditions}

The corrosion performance of the coating samples was evaluated exposing the coated specimens to UV radiation. Commercial UV-A lamps (center wavelength of radiation $340 \mathrm{~nm}$ ) was used for this purpose. The UV radiation, with a power density of $50 \mathrm{~mW} / \mathrm{cm}^{2}$, was applied to irradiate the metallic surface. The aging temperature was regulated at $30{ }^{\circ} \mathrm{C}$, in the presence of oxygen in the temperature range from $293 \mathrm{~K}$ to $303 \mathrm{~K}[10]$.

\section{Differential scanning calorimetry (DSC)}

Differential scanning calorimetry (DSC) was performed using a Shimadzu Differential Scanning Calorimeter (DSC-60), operating at temperatures from $20{ }^{\circ} \mathrm{C}$ to $300{ }^{\circ} \mathrm{C}$, and employing a heating rate of $20^{\circ} \mathrm{C} / \mathrm{min}$. The experiments were carried out under a constant flow of nitrogen with a sample weight of approximately $5 \mathrm{mg}$.

\section{Electrochemical Impedance Spectroscopy (EIS)}

In order to evaluate the response as UV stabilizer and anticorrosive coatings standard and composite of the two formulations prepared in this work, as a function of time, electrochemical impedance spectroscopy (EIS) was performed in an aqueous 3 wt. $\% \mathrm{NaCl}$ solution, at open circuit potential (OCP). Two samples were evaluated; $\mathrm{MP}_{1}$ standard, as reference, and $\mathrm{MP}_{2}$ composite. The employed working electrode was the carbon steel panel used as metallic substratum, with an area of $1 \mathrm{~cm}^{2}$. A platinum ring and saturated calomel electrode (SCE) were used as counter and reference electrodes, respectively. EIS measurements were performed with a PS 200 Biologic Potentiostat. The amplitude of the EIS perturbation signal was $10 \mathrm{mV}$, and the frequency ranged from $10^{-2}$ to $10^{5} \mathrm{~Hz}$. All the EIS analyses were conducted under potentiostatic conditions. The EIS measurements were carried out at unexposed and UV-exposed $(2000 \mathrm{~h})$ conditions, and at $1 \mathrm{~h}$ immersion in a saline solution, at a temperature of $298 \mathrm{~K}$. Then, the impedance spectra were analyzed by fitting the experimental data to an electrical equivalent circuit with the software V5.53 Lab Express .

\section{Scanning electron microscopy (SEM)}

Scanning electron microscopy (SEM) (S3000H, Hitachi) was employed to examine the surface morphology and cross-sectional morphology of the coatings. SEM measurements were carried out at $20 \mathrm{kV}$.

\section{Results and discussion}

\section{Differential scanning calorimetry (DSC)}

Measurements of $\mathrm{T}_{\mathrm{g}}$ provide a direct insight into the mobility of polymer chains; $\mathrm{T}_{\mathrm{g}}$ was taken as a midpoint in the specific heat transition [26]. $\mathrm{T}_{\mathrm{g}}$ is an important parameter for application of the epoxy resin thermoset. $T_{g}$ of the epoxy resin (DGEDDS) cured with primary diamine aromatic (MDA) as reference, and with 
the presence of $5 \mathrm{wt} . \%$ of titanium dioxide particle as additive, $\mathrm{MP}_{2}$, have been measured by DSC.

$\mathrm{DSC}$ analysis of reference sample, $\mathrm{MP}_{1}$, and composite sample, $\mathrm{MP}_{2}$, display $T_{\mathrm{g}}$ values in the experimental temperature ranging from 20 to $120^{\circ} \mathrm{C}$. A stack plot of DSC thermograms of the product is depicted in Fig. 6.

Clear single endothermic transitions appeared at the thermograms correspond to $T_{\mathrm{g}}$ transitions. The samples: Vstandard $\mathrm{X}$ and Vcomposite $\mathrm{X}$ have a $T_{\mathrm{g}}$ of $65{ }^{\circ} \mathrm{C}$ and $64{ }^{\circ} \mathrm{C}$, respectively.

The lowering of the $\mathrm{T}_{\mathrm{g}}$ values is attributed to $\mathrm{TiO}_{2}$ presence, which increases the free volume and consequently, a $\mathrm{T}_{\mathrm{g}}$ drop.

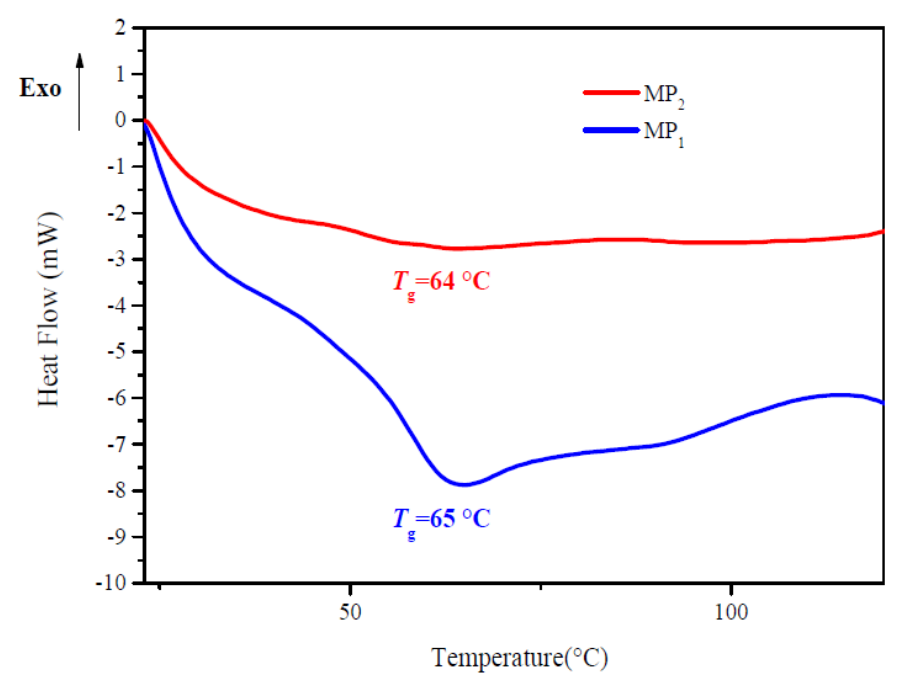

Figure 6. DSC curves of reference sample, $\mathrm{MP}_{1}$, and composite sample, $\mathrm{MP}_{2}$.

\section{Performance and degradation of the studied coating}

Several authors investigated the failure mechanism of different coating systems by electrochemical impedance spectroscopy (EIS) measurements. This procedure allows monitoring the behavior of coated surfaces, giving valuable information about both coating degradation and resistance to protect the metal surface in different corrosive environments [25, 27, 28].

\section{Impedance diagrams Bode plots}

The Bode plots exhibit two regions. The first high frequency represents the coating capacitance, and the other one, with low frequency, is generally attributed to the charge transfer process $[29,30]$.

Fig. 7 shows the Bode plots of $\mathrm{MP}_{1}$ standard epoxy and $\mathrm{MP}_{2}$ composite coatings with $2000 \mathrm{~h} \mathrm{UV}$ exposure, and without UV exposure, after $1 \mathrm{~h}$ immersion in a 3 wt. $\% \mathrm{NaCl}$ solution. The evaluation was carried out by measuring the impedance modulus $(/ \mathrm{Z} /)$.

It can be seen from Fig. 7 that the total impedance of standard epoxy coating, $\mathrm{MP}_{1}$, and composite epoxy coating, $\mathrm{MP}_{2}$, in the low frequency region $\left(10^{2}-10^{3} \mathrm{~Hz}\right)$, after 1 hour of immersion in $3 \mathrm{wt} . \% \mathrm{NaCl}$, was greater than that of the standard epoxy coating. 
Further, the impedance modulus at low frequency of $0.01 \mathrm{~Hz}\left(|\mathrm{Z}|_{0.01 \mathrm{~Hz}}\right)$ for the $\mathrm{MP}_{2}$ composite coating is significantly higher than that of the $\mathrm{MP}_{1}$ standard coating, after 1 hour of immersion in 3 wt. $\% \mathrm{NaCl}$; the $|\mathrm{Z}|_{0.01 \mathrm{~Hz}}$ value for $\mathrm{MP}_{1}$ standard coating and $\mathrm{MP}_{2}$ composite coating is $1,8 \times 10^{4}$ and $1,02 \times 10^{5} \Omega . \mathrm{cm}^{2}$, respectively. The higher $|\mathrm{Z}|_{0.01 \mathrm{~Hz}}$ value of $\mathrm{MP}_{2}$ composite coating, compared to $\mathrm{MP}_{1}$ standard coating, shows that composite coatings have higher barrier properties against electrolyte diffusion through the coating.

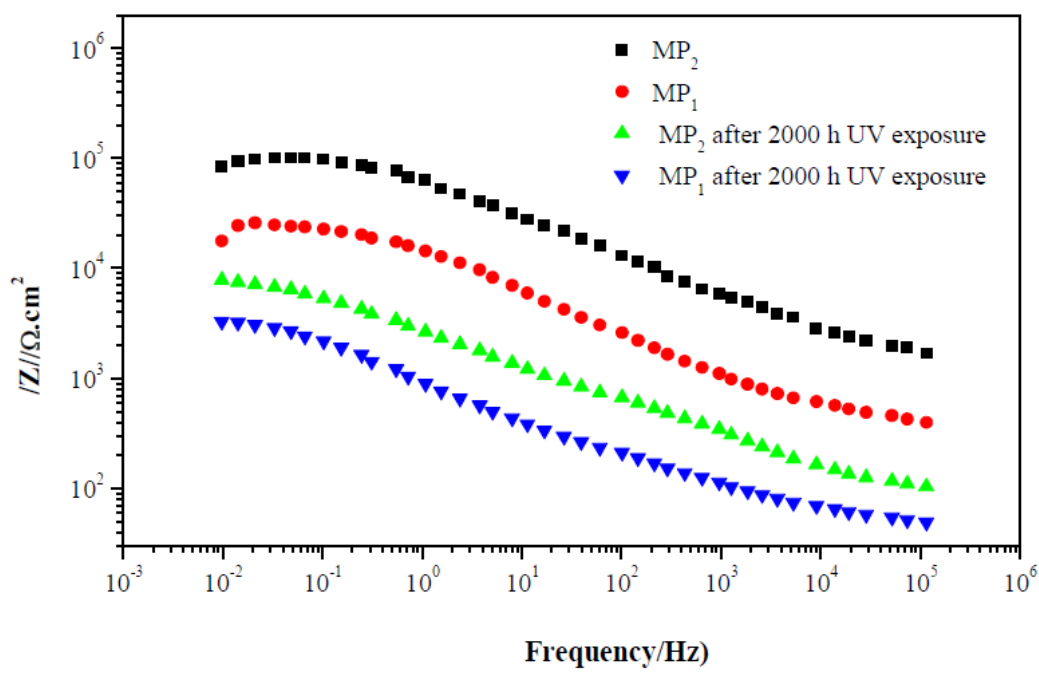

Figure 7. Impedance diagrams (Bode plots) of standard epoxy coating, $\mathrm{MP}_{1}$, and composite epoxy coating, $\mathrm{MP}_{2}$, after $1 \mathrm{~h}$ of immersion of carbon steel in $3 \mathrm{wt} . \% \mathrm{NaCl}$ and after $2000 \mathrm{~h} \mathrm{UV}$ exposure and $1 \mathrm{~h}$ immersion in $3 \mathrm{wt} . \% \mathrm{NaCl}$.

After $2000 \mathrm{~h} \mathrm{UV}$ exposure and $1 \mathrm{~h}$ immersion in $3 \mathrm{wt} . \% \mathrm{NaCl}$, degradation of the standard coating occurs and the $|\mathrm{Z}|_{0.01 \mathrm{~Hz}}$ value decreases to $3,3 \times 10^{3} \mathrm{ohm} . \mathrm{cm}^{2}$, due to the permeation of a corrosive solution into the coating.

On the other side, although the $|\mathrm{Z}|_{0.01 \mathrm{~Hz}}$ value of the composite coating decreases after $2000 \mathrm{~h} \mathrm{UV}$ exposure and $1 \mathrm{~h}$ immersion in $3 \mathrm{wt} . \% \mathrm{NaCl}$ (which is about 8,8 $\times 10^{3} \Omega . \mathrm{cm}^{2}$ ), it is still much higher than the standard coating.

Moreover, the /Z/ module at high frequency for the composite coating is significantly higher than the standard coating, after 1 hour of immersion in $3 \mathrm{wt}$. \% $\mathrm{NaCl}$, and after $2000 \mathrm{~h} \mathrm{UV}$ exposure and $1 \mathrm{~h}$ immersion in $3 \mathrm{wt} . \% \mathrm{NaCl}$.

In addition, $\mathrm{MP}_{2}$ composite coating sample shows higher impedance than $\mathrm{MP}_{1}$ standard coating at low frequency, indicating that $\mathrm{MP}_{2}$ provides higher protective performance.

These results signify that the corrosion protection performance of the composite coating, after $2000 \mathrm{~h} \mathrm{UV}$ and $1 \mathrm{~h}$ immersion in 3 wt. $\% \mathrm{NaCl}$, significantly improves via addition of Titanium Dioxide $\left(\mathrm{TiO}_{2}\right)$.

$\mathrm{TiO}_{2}$ enhances the barrier properties of the epoxy coating against the diffusion of corrosive agents at the metal/coating interface. 


\section{Impedance diagrams Nyquist plots}

The Nyquist plots are composed of two loops. The first high frequency (HF) represents the coating capacitance and the other one, with low frequency (LF), is attributed to the charge transfer process [31].

Fig. 8 shows the Nyquist plots of $\mathrm{MP}_{1}$ standard epoxy and $\mathrm{MP}_{2}$ composite coatings, with $2000 \mathrm{~h} \mathrm{UV}$ exposure, and without UV exposure, after $1 \mathrm{~h}$ immersion in a 3 wt. \% $\mathrm{NaCl}$ solution.

Further, the impedance data are modeled via electrical equivalent circuit [32], shown in Fig. 9, and the extracted electrochemical parameters are presented in Table 1 .

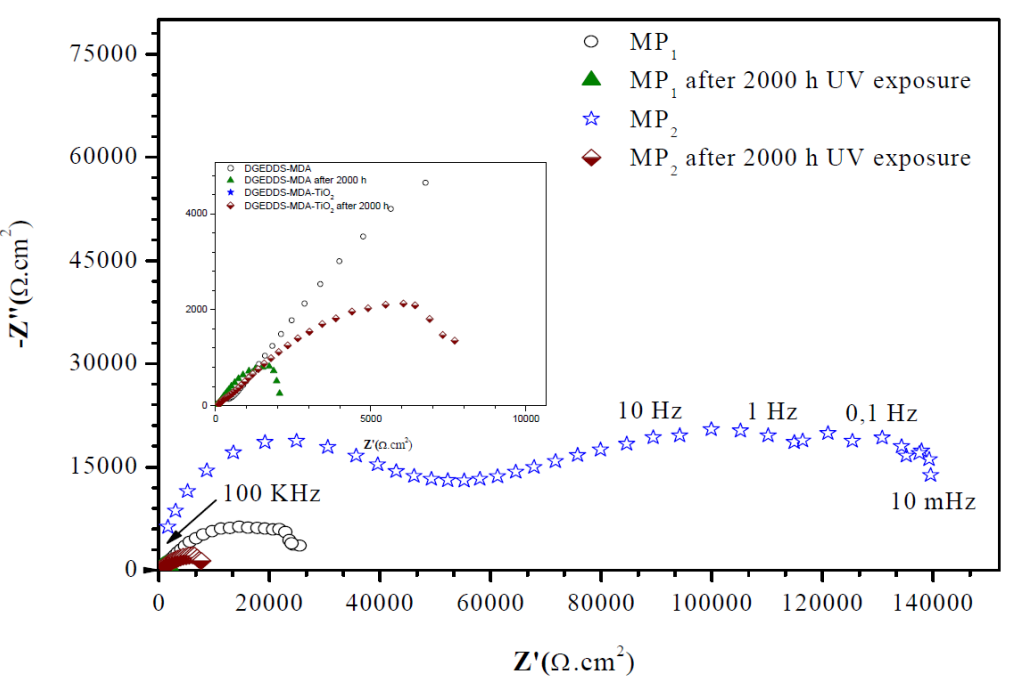

Figure 8. Impedance diagrams (Nyquist plots) of $\mathrm{MP}_{1}$ standard epoxy coating and $\mathrm{MP}_{2}$ composite epoxy coating, after $1 \mathrm{~h}$ of immersion of carbon steel in $3 \mathrm{wt} \% \mathrm{NaCl}$, and after $2000 \mathrm{~h}$ UV exposure and $1 \mathrm{~h}$ immersion in $3 \mathrm{wt} . \% \mathrm{NaCl}$.

The equivalent electrical circuit is often used to analyze the impedance spectra of a metal/coating system. In this paper, an $R_{s}\left(Q_{\text {coat }}\left(R_{\text {pore }}\left(Q_{d l} R_{c t}\right)\right)\right.$ circuit model was used to model the coatings behavior, where $\mathrm{R}_{\mathrm{S}}$ represents the electrolyte resistance, $\mathrm{Q}_{\text {coat }}$ and $\mathrm{R}_{\text {pore }}$ are the coating capacitance and pore resistance, respectively, and double layer capacity $\left(\mathrm{C}_{\mathrm{dl}}\right)$ and charge transfer resistance $\left(\mathrm{R}_{\mathrm{ct}}\right)$ are used to simulate the electrochemical process at the metal interface (Faradic reaction). The electrochemical parameters are given in Table 1.

\section{$Q_{\text {coat }}$}

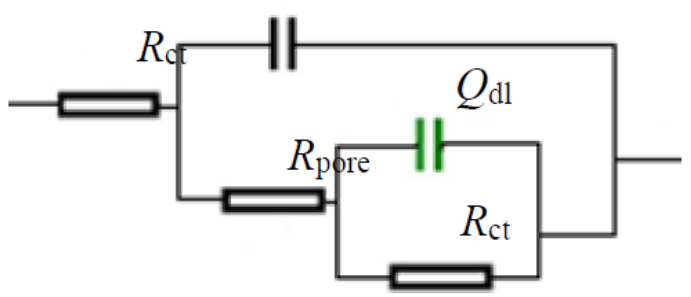

Figure 9. Proposed equivalent circuit for numerical simulation of the EIS measurements. 
Table 1. Different electrochemical parameters extracted from impedance data of $\mathrm{MP}_{1}$ standard epoxy coating and $\mathrm{MP}_{2}$ composite epoxy coating, after $1 \mathrm{~h}$ of immersion of carbon steel in $3 \mathrm{wt} . \% \mathrm{NaCl}$, and after $2000 \mathrm{~h} \mathrm{UV}$ exposure and $1 \mathrm{~h}$ immersion in $3 \mathrm{wt}$. $\% \mathrm{NaCl}$.

\begin{tabular}{lccccc}
\hline Samples & $\begin{array}{c}R_{\mathrm{s}} \\
\left(\Omega . \mathrm{cm}^{2}\right)\end{array}$ & $\begin{array}{c}Q_{\text {coat }} \\
\left(\mu \mathrm{F} / \mathrm{cm}^{2}\right)\end{array}$ & $\begin{array}{c}R_{\text {pore }} \\
\left(\Omega . \mathrm{cm}^{2}\right)\end{array}$ & $\begin{array}{c}Q_{\mathrm{dl}} \\
\left(\mu \mathrm{F} / \mathrm{m}^{2}\right)\end{array}$ & $R_{\mathrm{ct}}\left(\Omega . \mathrm{cm}^{2}\right)$ \\
\hline $\mathrm{MP}_{1}$ & 286 & 1.41 & 5153 & 1.02 & 26971 \\
$\mathrm{MP}_{1}-2000 \mathrm{~h} \mathrm{UV}$ & 20 & 34 & 656 & 2.8 & 1960 \\
$\mathrm{MP}_{2}$ & 198 & 0.91 & 33792 & 0.11 & 140975 \\
$\mathrm{MP}_{2}-2000 \mathrm{~h} \mathrm{UV}$ & 71 & 19,6 & 718 & 0.29 & 9630 \\
\hline
\end{tabular}

Double layer capacitance and coating capacitance $\left(Q_{\mathrm{dl}}, Q_{\text {coat }}\right)$

The double layer capacitance $\left(\mathrm{Q}_{\mathrm{dl}}\right)$, which is related to the distribution of ionic charges at the metal/coatings interface [33], is significantly lower for $\mathrm{MP}_{2}$ composite coating, after $1 \mathrm{~h}$ of immersion of carbon steel in $3 \mathrm{wt} . \% \mathrm{NaCl}$, and after $2000 \mathrm{~h} \mathrm{UV}$ exposure and $1 \mathrm{~h}$ immersion in $3 \mathrm{wt} . \% \mathrm{NaCl}$. Besides, $\mathrm{Q}_{\mathrm{dl}}$ of $\mathrm{MP}_{2}$ composite coating is lower than $\mathrm{MP}_{1}$ standard coating. The $\mathrm{Q}_{\mathrm{dl}}$ value increases after $2000 \mathrm{~h} \mathrm{UV}$ exposure and $1 \mathrm{~h}$ immersion in $3 \mathrm{wt} . \% \mathrm{NaCl}$, due to the expansion of active sites [34].

The coating capacitance $\left(\mathrm{Q}_{\text {coat }}\right)$ for $\mathrm{MP}_{2}$ composite coating is lower than $\mathrm{MP}_{1}$ standard coating, after 1 hour of immersion of carbon steel in a $3 \mathrm{wt} . \% \mathrm{NaCl}$ solution. This is because $\mathrm{TiO}_{2}$ fills the micropores and decreases the water uptake into the coating. The variation of $\mathrm{Q}_{\text {coat }}$ proved the degradation of two of the $\mathrm{MP}_{1}$ matrix coatings after $2000 \mathrm{~h}$ exposure to $\mathrm{UV}$ and $1 \mathrm{~h}$ immersion in corrosive media, and limited degradation in the $\mathrm{MP}_{2}$ coating. $\mathrm{Q}_{\text {coat }}$ increased with increasing UV exposure time, which indicated, after immersion in corrosive media, that the penetration of water into the coating/metal interface was accelerated, causing an increase in the microcracks. The increase of microcracks facilitates the penetration of water into the interface. The dielectric constant of the coating increased with diffusion of water into the coating/metal interface.

\section{Coating resistance and charge transfer resistance $\left(\mathrm{R}_{\text {pore, }}, \mathrm{R}_{\mathrm{ct}}\right)$}

The results presented in Table 1 show that the higher value of $R_{\text {pore }}$ and $R_{c t}$ for $\mathrm{MP}_{2}$ composite coating than that of the $\mathrm{MP}_{1}$ standard coating can be explained by the good dispersibility of $\mathrm{TiO}_{2}$ in the coating and improving coating electrical resistance against the transfer of corrosive species through the pores of the coating. The increase in $\mathrm{R}_{\text {coat }}$ and $\mathrm{R}_{\mathrm{ct}}$ indicates the effect of $\mathrm{TiO}_{2}$ on the decrease of the penetration of corrosive species into the coating/metal interface, through decreasing coating porosity [35].

However, $R_{\text {pore }}$ and $R_{c t}$ values of coatings decreased with an increase in UV exposure and immersion time, which caused the creation of microcracks. The MP 1 standard coating shows that the $R_{\text {pore }}$ value decreases after $2000 \mathrm{~h}$, which is attributed to the uptake of electrolytes into the coating. However, $\mathrm{MP}_{2}$ composite coating shows slight changes in $\mathrm{R}_{\text {pore }}$ value. The results show that $\mathrm{TiO}_{2}$ prevents the degradation of coatings. In addition, $\mathrm{TiO}_{2}$ prevents the propagation of microcracks and does not allow water and corrosive species to penetrate into the 
metal/coating interface. Besides, $\mathrm{TiO}_{2}$ fills micro pores of the coating and decreases the possible sites of microcracks formation.

\section{EIS characteristics of coatings after $U$ V exposure}

The EIS results approved the mechanism proposed for preventing the degradation of coating under UV exposure (Fig 10).

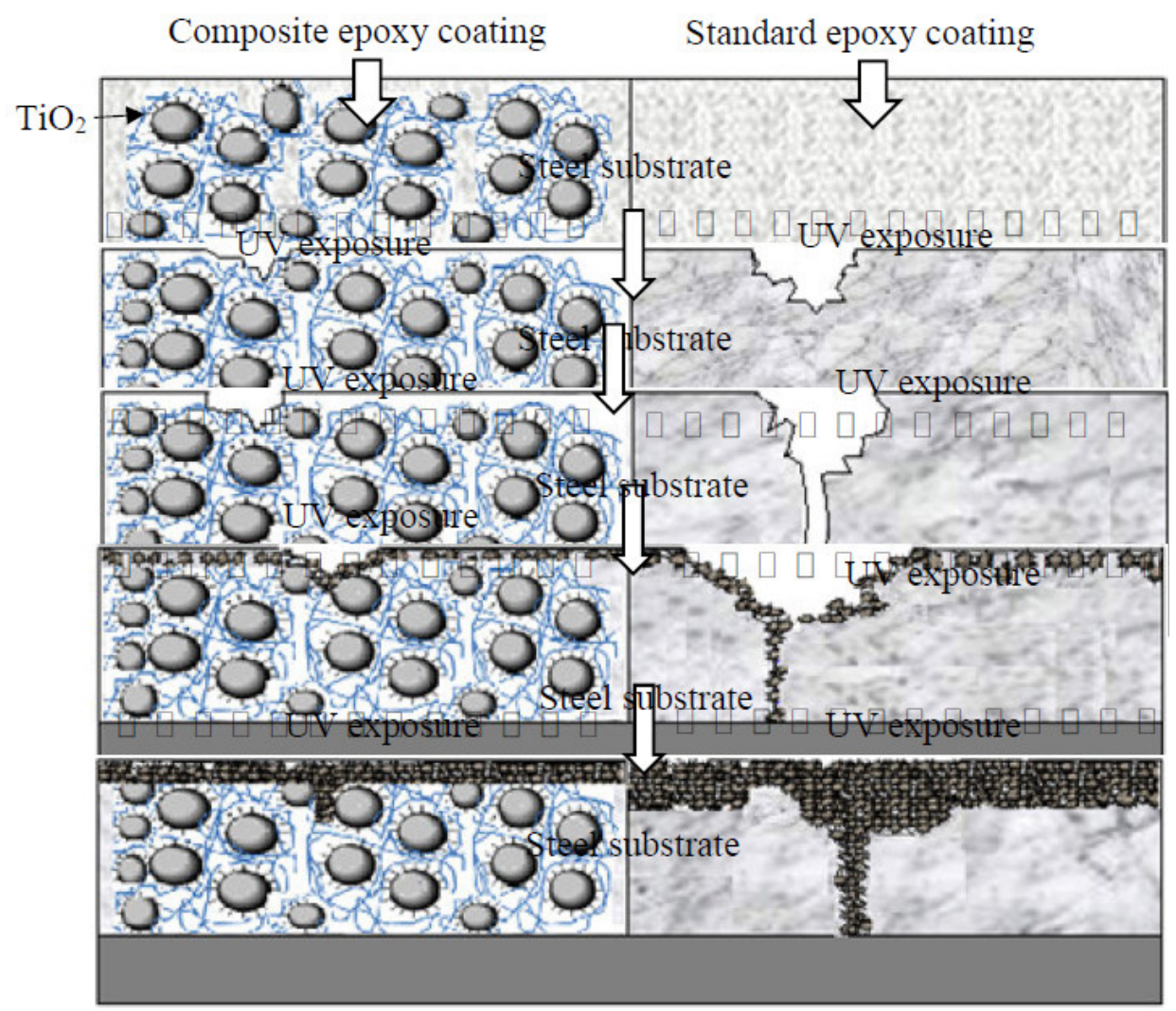

Figure 10. Schematic illustration of the protection mechanism by standard epoxy coatings and composite epoxy coatings, at different irradiation periods on carbon steel substrates.

By increasing the exposure time up to $2000 \mathrm{~h}$, some variations were observed in the resistances of the coatings, showing the rate of degradation by UV radiation. The resistance of the two studied coatings decreased more than $10^{3}$ times, after $2000 \mathrm{~h}$ UV exposure and $1 \mathrm{~h}$ immersion in $3 \mathrm{wt} . \% \mathrm{NaCl}$.

The surface of $\mathrm{MP}_{1}$ standard coating had many microcracks. After $2000 \mathrm{~h}$ of UV exposure to the corrosive media, the corrosive agent diffused into the metal/coating interface. Penetration of the corrosive agent led to a decrease in the impedance of DGEDDS-MDA coating. With an increasing immersion time, all microcracks were filled by 3 wt. $\% \mathrm{NaCl}$.

After $1 \mathrm{~h}$ immersion, the corrosion products, such as rust, filled microcracks temporarily. These products limit the penetration of corrosive agents into the metal/coating interface and lead to the impedance increase of $\mathrm{MP}_{1}$ coating of about one order. With increasing immersion times, these products cannot limit the penetration of the corrosive agent, because of their porous nature. Therefore, the 
impedance of $\mathrm{MP}_{2}$ coating after $2000 \mathrm{~h} \mathrm{UV}$ exposure and $1 \mathrm{~h}$ immersion in corrosive media was higher than $\mathrm{MP}_{1}$ coating. $\mathrm{MP}_{2}$ coating had a stable impedance, because the $\mathrm{TiO}_{2}$ nanoparticles were more than those of the $\mathrm{MP}_{1}$ coating, which limited the penetration of corrosive agents. Impedance of the $\mathrm{MP}_{1}$ coating against UV irradiation decreased severally, so it completely lost its protective performance.

\section{Surface morphology of coatings before and after $U$ V exposure}

The microstructure of cross sectional surfaces of two carbon steel panels was analyzed for change in morphology, before and after $2000 \mathrm{~h}$ of UV exposure, by SEM, and their micrographs are shown in Fig. 11.

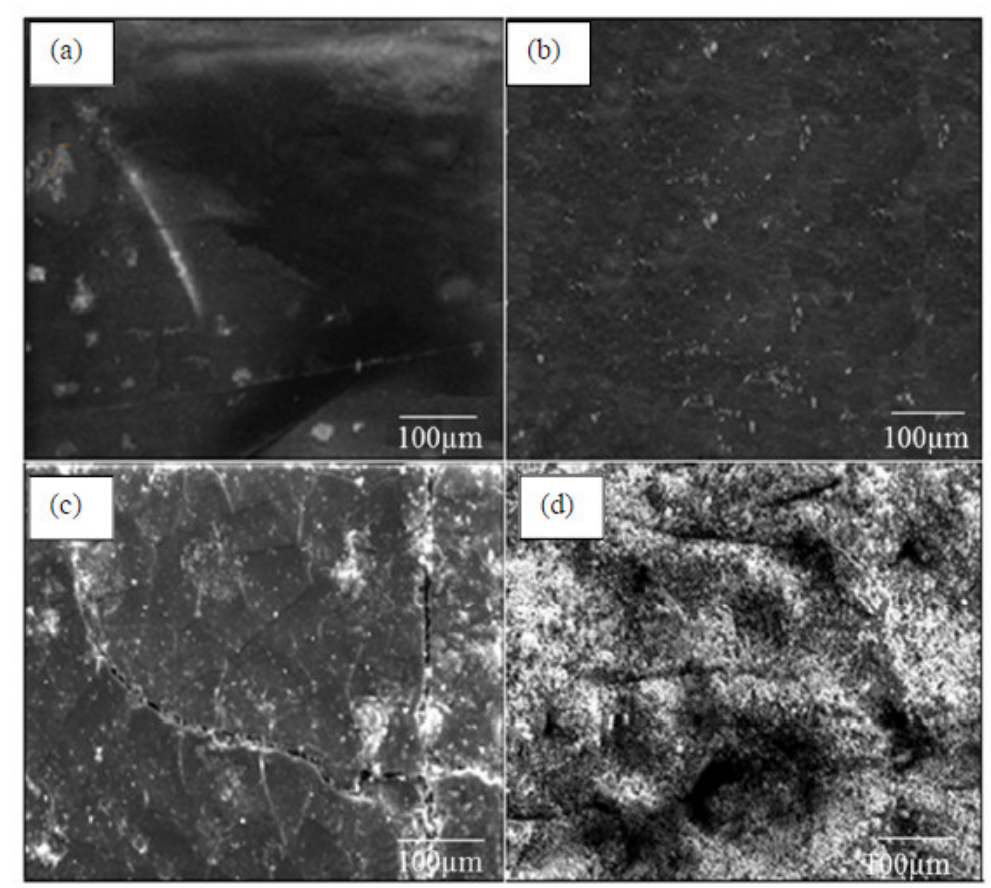

Figure 11. SEM images before and after $2000 \mathrm{~h}$ UV exposure.

As shown in Fig. 11a, the coating without $\mathrm{TiO}_{2}$ nanoparticles was very smooth for the matrix with $\mathrm{MP}_{1}$ standard coating $[36,37]$. However, when 5 wt. $\%$ of $\mathrm{TiO}_{2}$ nanoparticles were introduced, the coatings displayed a rough surface. Some micron-sized protrusions were observed to be embedded in the $\mathrm{MP}_{2}$ coatings (Fig. $11 b)$.

The standard coating, after $2000 \mathrm{~h}$ UV exposure, shows micro cracks on the surface. The surface of the sample is severely damaged after $2000 \mathrm{~h}$ of UV exposure. The micro cracks coating surface becomes deep and broaden during UV exposure, as shown in Fig. 11 (c). The surface micro cracks in degraded areas significantly decreased when titanium dioxide was added to the coating. Nevertheless, micro cracks in the coating were invisible after $2000 \mathrm{~h} \mathrm{UV}$ exposure in $\mathrm{MP}_{2}$ coating, as shown in Fig 11 (d). It seems that titanium dioxide decreases UV degradation in the coatings. 


\section{Conclusions}

We have presented two-matrix coatings $\mathrm{MP}_{1}$ standard and $\mathrm{MP}_{2}$ composite coating for protection of carbon steel substrates. The composite coating was shown to efficiently protect carbon steel substrate, due to its enhanced barrier properties, compared to the standard coating.

The main findings of this study can be drawn as follow:

- DSC analysis of the $\mathrm{MP}_{1}$ standard sample possessed a higher glass transition temperature, compared to the $\mathrm{MP}_{2}$ composite sample.

- The impedance diagrams, Bode and Nyquist plots study confirmed that $\mathrm{TiO}_{2}$ can fill micro pores and limit penetration of water into the coating.

- SEM results and electrochemical measurements show that the degradation of standard coating with many microcracks happened after $2000 \mathrm{~h} \mathrm{UV}$ exposure, but microcracks were not observed on the surface of the composite coating, with 5 wt. \% Titanium Dioxide.

\section{References}

1. Yuan X, Yue Z, Liu Z, et al. Comparison of the failure mechanisms of silicone-epoxy hybrid coatings on type A3 mild steel and 2024 Al-alloy. Progress in Organic Coatings. 2016;90:101-13. https://doi.org/10.1016/j.porgcoat.2015.10.004.

2. Verma C, Olasunkanmi LO, Akpan ED, et al. Epoxy resins as anticorrosive polymeric materials: A review. Reactive and Functional Polymers. 2020: 104741. https://doi.org/10.1016/j.reactfunctpolym.2020.104741.

3. Charitha BP, Chenan A, Rao P. Enhancement of surface coating characteristics of epoxy resin by dextran: an electrochemical approach. Indust \& Engin Chem Resear. 2017;56:1137-47. https://doi.org/10.1021/acs.iecr.6b03274.

4. Hang TTX, Truc TA, Nam T, et al. Corrosion protection of carbon steel by an epoxy resin containing organically modified clay. Surf Coat Techn. 2007;201:7408-15. https://doi.org/10.1016/j.surfcoat.2007.02.009\.

5. Dagdag O, Guo L, Safi Z, et al. Epoxy resin and $\mathrm{TiO} 2$ composite as anticorrosive material for carbon steel in 3\% $\mathrm{NaCl}$ medium: Experimental and computational studies. J Molec Liq. 2020;317:114249. https://doi.org/10.1016/j.molliq.2020.114249.

6. Rathish RJ, Dorothy R, Joany R, et al. Corrosion resistance of nanoparticleincorporated nano coatings. Euro Chem Bul. 2013;2:965-70.

7. Ghanbari A, Attar M. A study on the anticorrosion performance of epoxy nanocomposite coatings containing epoxy-silane treated nano-silica on mild steel substrate. J Ind Eng Chem. 2015;23:145-53. https://doi.org/10.1016/j.jiec.2014.08.008.

8. Dagdag O, Hsissou R, El Harfi A, et al. Development and Anti-corrosion Performance of Polymeric Epoxy Resin and their Zinc Phosphate Composite on 15CDV6 Steel in 3wt\% NaCl: Experimental and Computational Studies. J Bio-and Tribo-Corr. 2020;6:1-9. https://doi.org/10.1007/s40735-020-00407-1.

9. González-García Y, González S, Souto R. Electrochemical and structural properties of a polyurethane coating on steel substrates for corrosion protection. Corr Sci. 2007; 49:3514-26. 
https://doi.org/10.1016/j.corsci.2007.03.018.

10. Dagdag O, El Harfi A, El Gana L, et al. Designing of phosphorous based highly functional dendrimeric macromolecular resin as an effective coating material for carbon steel in $\mathrm{NaCl}$ : Computational and experimental studies. J App Polymer Sci. 2020;138:49673. https://doi.org/10.1002/app.49673.

11. Sangermano M, Roppolo I, Shan G, et al. Nanocomposite epoxy coatings containing rare earth ion-doped LaF3 nanoparticles: Film preparation and characterization. Prog Org Coat. 2009;65:431-4. https://doi.org/10.1016/j.porgcoat.2009.03.007.

12. Dagdag O, Hsissou R, El Harfi A, et al. Epoxy resins and their zinc composites as novel anti-corrosive materials for copper in 3\% sodium chloride solution: Experimental and computational studies. J Mol Liq. 2020;315:113757. https://doi.org/10.1016/j.molliq.2020.113757.

13. Ramezanzadeh B, Attar M. Studying the effects of micro and nano sized $\mathrm{ZnO}$ particles on the corrosion resistance and deterioration behavior of an epoxypolyamide coating on hot-dip galvanized steel. Prog Org Coatings. 2011;71:314-28. https://doi.org/10.1016/j.porgcoat.2011.03.026.

14. Xavier JR, Nallaiyan R. Application of EIS and SECM studies for investigation of anticorrosion properties of epoxy coatings containing $\mathrm{ZrO} 2$ nanoparticles on mild steel in $3.5 \% \mathrm{NaCl}$ solution. J Failure Analysis Preven. 2016;16:1082-91. https://doi.org/10.1007/s11668-016-0187-x.

15. Schem M, Schmidt T, Gerwann J, et al. CeO2-filled sol-gel coatings for corrosion protection of AA2024-T3 aluminium alloy. Corr Sci. 2009;51:230415. https://doi.org/10.1016/j.corsci.2009.06.007.

16. Yu H, Wang L, Shi Q, et al. Study on nano-CaCO3 modified epoxy powder coatings. Progress in Organic coatings. 2006:55:296-300. https://doi.org/10.1016/j.porgcoat.2006.01.007.

17. Dhoke SK, Sinha TJM, Khanna A. Effect of nano-A12O3 particles on the corrosion behavior of alkyd based waterborne coatings. J Coat Techn Research. 2009;6:353-68. https://doi.org/10.1007/s11998-008-9127-3.

18. Dolatzadeh F, Moradian S, Jalili M M. Influence of various surface treated silica nanoparticles on the electrochemical properties of $\mathrm{SiO} 2 /$ polyurethane nanocoatings. Corr $\quad$ Sci. $2011 ; 53: 4248-57$. https://doi.org/10.1016/j.corsci.2011.08.036

19. Dong Y, Zhang Q, Su X, et al. Preparation and investigation of the protective properties of bipolar coatings. Prog Org Coatings. 2013;76:662-9. https://doi.org/10.1016/j.porgcoat.2012.12.007.

20. Ghasemi-Kahrizsangi A, Shariatpanahi H, Neshati J, et al. Degradation of modified carbon black/epoxy nanocomposite coatings under ultraviolet exposure. Appl Surf Sci https://doi.org/10.1016/j.apsusc.2015.06.029

21. Erramli H, Dagdag O, Safi Z, et al. Trifunctional epoxy resin as anticorrosive material for carbon steel in $1 \mathrm{M} \mathrm{HCl}$ : Experimental and computational studies. Surf Interf. 2020;21:100707. https://doi.org/10.1016/j.surfin.2020.100707.

22. Dagdag O, El Harfi A, Safi Z, et al. Fabrication on designing of a macromolecular epoxy resin as anti-corrosive coating material for 
electrocatalytically deposited cadmium on $15 \mathrm{CDV} 6$ steel in $3 \% \mathrm{NaCl}$ solution. J Mat Res Techn. 2020;9:5549-63. https://doi.org/10.1016/j.jmrt.2020.03.080.

23. Dagdag O, El Gouri M, El Mansouri A, et al. Rheological and Electrical Study of a Composite Material Based on an Epoxy Polymer Containing Cyclotriphosphazene.

Polymers.2020;12:921. https://doi.org/10.3390/polym12040921.

24. Dagdag O, Hsissou R, El Harfi A, et al. Fabrication of polymer based epoxy resin as effective anti-corrosive coating for steel: Computational modeling reinforced experimental studies. Surf Interf. 2020;18:100454. https://doi.org/10.1016/j.surfin.2020.100454

25. Dagdag O, Berisha A, Safi Z, et al. Highly durable macromolecular epoxy resin as anticorrosive coating material for carbon steel in $3 \% \mathrm{NaCl}$ : Computational supported experimental studies. J Appl Polym Sci. 2020; 49003. https://doi.org/10.1002/app.49003.

26. Yurov Y, Laurinas VC, Eremin E. Determination of glass transition temperature for polymers by methods of thermoactivation spectroscopy. In IOP Conference Series: Mater SciEng. 2016:012018.

27. Dagdag O, Hamed O, Erramli H, et al. Anticorrosive performance approach combining an epoxy polyaminoamide-zinc phosphate coatings applied on sulfo-tartaric anodized aluminum alloy 5086. J Bio-and Tribo-Corr. 2018;4:52. https://doi.org/10.1007/s40735-018-0168-6.

28. Dagdag O, El Gana L, Hamed O, et al. Anticorrosive formulation based of the epoxy resin-polyaminoamide containing zinc phosphate inhibitive pigment applied on sulfo-tartaric anodized AA 7075-T6 in $\mathrm{NaCl}$ medium. J Bio-and Tribo-Corr. 2019;5:25.

29. Dagdag O, El Harfi A, Essamri A, et al. Phosphorous-based epoxy resin composition as an effective anticorrosive coating for steel. Int $\mathrm{J}$ Industr Chem. 2018;9:231-40. https://doi.org/10.1007/s40090-018-0152-5 .

30. Dagdag O, El Harfi A, El Gana L, et al. The role of zinc phosphate pigment in the anticorrosion properties of bisphenol A diglycidyl ether-polyaminoamide coating for aluminum alloy AA2024-T3. J Bio Tribo Corr. 2019;5:7. https://doi.org/10.1007/s40735-018-0200-x.

31. Montemor M, Snihirova D, Taryba M, et al. Evaluation of self-healing ability in protective coatings modified with combinations of layered double hydroxides and cerium molibdate nanocontainers filled with corrosion inhibitors. Electrochim Acta. 2012;60:31-40. https://doi.org/10.1016/j.electacta.2011.10.078.

32. Dagdag O, Hsissou R, Berisha A, et al. Polymeric-based epoxy cured with a polyaminoamide as an anticorrosive coating for aluminum 2024-T3 surface: experimental studies supported by computational modeling. J Bio Tribo Corr. 2019;5:58. https://doi.org/10.1007/s40735-019-0251-7.

33. Dong Y, Liu Q, Zhou Q. Time-dependent protection of ground and polished $\mathrm{Cu}$ using graphene film. Corr Sci. 2015;90:69-75. https://doi.org/10.1016/j.corsci.2014.09.018

34. Wu LK, Zhang JT, Hu JM, et al. Improved corrosion performance of electrophoretic coatings by silane addition. Corr Sci. 2012;56:58-66. 
https://doi.org/10.1016/j.corsci.2011.11.018.

35. Ramezanzadeh B, Ahmadi A, Mahdavian M. Enhancement of the corrosion protection performance and cathodic delamination resistance of epoxy coating through treatment of steel substrate by a novel nanometric sol-gel based silane composite film filled with functionalized graphene oxide nanosheets. Corr Sci. 2016;109:182-205. https://doi.org/10.1016/j.corsci.2016.04.004 .

36. Dagdag O, Hanbali G, Khalaf B, et al. Dual component polymeric epoxypolyaminoamide based zinc phosphate anticorrosive formulation for 15CDV6 steel. Coatings. 2019;9:463. https://doi.org/10.3390/coatings9080463.

37. Dagdag O, Berisha A, Safi Z, et al. DGEBA-polyaminoamide as effective anti-corrosive material for 15CDV6 steel in $\mathrm{NaCl}$ medium: Computational and experimental studies. J Appl Polym Sci. 2020;137:48402. https://doi.org/10.1002/app.48402. 